\title{
Measuring periodontitis in population studies: a literature review
}

\author{
Medição de periodontite em estudos populacionais: \\ uma revisão de literatura
}

\section{Abstract}

Case definitions used to identify periodontitis significantly affect the prevalence and risk estimates from population studies. A plethora of definitions has been employed by researchers since the 1940s. The variation in disease definitions affects the comparability and validity of the estimates. This study aimed to review case definitions of periodontitis in prevalence and risk population studies. PubMed and Medline were searched for the following keywords: "Periodontitis" AND "cross sectional/case control/epidemiology". Studies were selected and reviewed. We found that there is a variety of case definitions being employed in prevalence and risk factor studies. Starting with the index systems, the definitions have been influenced by our understanding of the pathogenesis of the disease. There is a need for a uniform case definition for prevalence surveys and population-specific definitions for association studies.

Key words: Periodontitis; case definition; population studies; epidemiology

\section{Resumo}

A definição diagnóstica utilizada para identificar periodontite determina em grande parte a prevalência e as estimativas de risco a partir de estudos populacionais. Uma grande variedade de definições tem sido utilizada por pesquisadores desde a década de 1940. Esta variabilidade de definição da doença afeta a comparação e a validade das estimativas. Este estudo teve por objetivo revisar as definições de periodontite em estudos populacionais de prevalência e de risco. Realizou-se uma busca eletrônica na base de dados PubMedMedlinecom as plavraschave: "Periodontitis" AND "crosssectional/case control/epidemiology". Os artigos foram selecionados e analisados. Este trabalho de revisão encontrou grande variedade de definição de casos usada em estudos de prevalência e de fatores de risco.A partir dos sistemas de indexação, as definições foram influenciadas pelo então entendimento corrente da patogênese da doença. Há necessidade de uma definição de caso uniforme para inquéritos de prevalência e definições populacionais específicas para estudos de associação.

Palavras-chave: Periodontite; definição de caso; estudos populacionais; epidemiologia

\section{Shaju Jacob Pa}

- Chhattisgarh Dental College and Research Institute, Rajnandgaon, Chhattisgarh, India

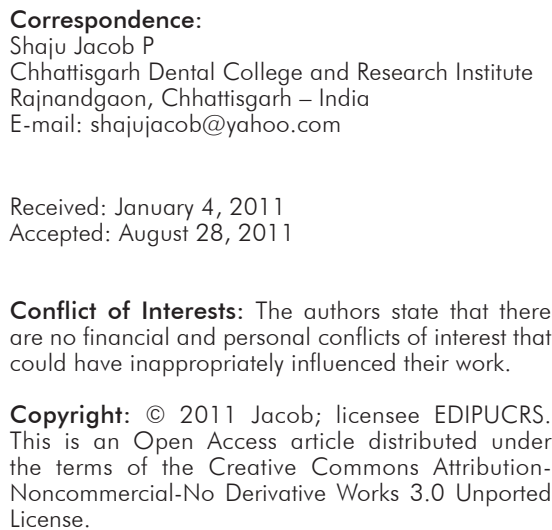

Conflict of Interests: The authors state that there are no financial and personal conflicts of interest that could have inappropriately influenced their work.

Copyright: (C) 2011 Jacob; licensee EDIPUCRS. This is an Open Access article distributed under the terms of the Creative Commons AttributionNoncommercial-No Derivative Works 3.0 Unported License. 


\section{Introduction}

Periodontitis is a chronic infectious disease of the supporting tissues around the teeth leading to its progressive destruction. The identification of periodontitis is based on clinical findings including the presence and extent of periodontal pockets, loss of clinical attachment, pattern and extent of alveolar bone loss, or a combination of these findings. A standard case definition of a disease is a fundamental requirement for population-based surveillance of the disease (1). Multiple case definitions have been used in population studies on periodontitis, including many which have been developed arbitrarily. Index systems were popular in the 1970s and became less valid as our understanding of the pathogenesis of the disease improved (1-5). The influence of changing concepts for the clinical diagnosis of the disease probably resulted in the non-standardization of the case definition in population studies (6-8). As globalization progresses, the need for a uniform case definition of periodontitis increases.

The aim of this study was to review the different case definitions used in studies on periodontitis' epidemiology.

\section{Methods}

PubMed and Medline were searched using the key words, "Periodontitis" AND "cross sectional/case control/epidemiology". Only studies published in English from 1985 were included (except for two older publications for index definition). Population-based prevalence studies and association studies using a clearly stated case definition to identify periodontitis, were selected. A population based study was identified with the following definition: "a study of a group of individuals taken from the general population who share a common characteristic, such as age, sex, or health condition". Studies which gave a rationale for the use of their case definition were reviewed. Other articles, which had employed a case definition without giving the rationale for its use, were included but not reviewed in depth (on the aspect of the definition's relevance to the study). Definitions for gingival disease were not included in the review. Thirty-nine publications were reviewed for the case definition used in the studies.

\section{Index systems of defining periodontitis}

Since 1945, special systems (9) have been introduced for measuring the health and disease of periodontal tissues. These systems have aimed at expressing the gingival and/or periodontal states in numerical values or indices. Such an index is defined as a number on a graduated scale that provides information on the relative condition of an individual regarding the disease under investigation. The index based systems were developed to simplify the identification of periodontal disease in a person. It was developed at a time when gingivitis and periodontitis were regarded by many as a continuum, where longstanding gingivitis eventually progresses to periodontitis (10).

Russell (11) introduced the periodontal index in 1956 to measure stages of periodontal disease and to measure its pre- valence in different population groups. Each tooth was scored as no disease, gingivitis, periodontitis, or advanced periodontitis, and the average score of all teeth combined was the individual's score. The average individual score was the population score. No PD (probing depth) or attachment level was recorded because according to Russell "probing added little and proved to be troublesome focus of examiner disagreement".

PI was used extensively in epidemiological surveys of populations including in NHANES I but became outdated because of the following reasons (12):

- Gingivitis is not early periodontitis;

- PD, clinical attachment level (CAL) and radiographic bone loss were not considered.

Subjectively, there is no clear distinction between gingivitis and periodontitis (13);

Unwarranted weights were assigned to different categories of disease (14).

Ramjford introduced the Periodontal Disease Index (PDI) in 1967. He used partial recordings in his assessment of disease by examining a total of six teeth, which are now called the Ramjford teeth (15). He introduced the measure of CAL from the Cementoenamel junction (CEJ), which serves as a fixed point. Each selected tooth was given a score based on the severity of the CAL, and the average score of all the selected teeth resulted in the individual's score. PDI also calculated tooth scores for calculus, occlusal attrition, mobility, and proximal contacts but this scoring did not affect the scoring for periodontitis. Although PDI is rarely used these days, the following two aspects of PDI continue to be used commonly: selection of the Ramjford teeth and method of measuring probing depth and attachment level.

The Community Periodontal Index for Treatment Needs (CPITN) was recommended by the WHO, to assess the treatment needs of a population. CPITN is a cumulative index introduced by Ainamo in 1983. Periodontal health, gingival bleeding, calculus, shallow pockets $(3.5-5.5 \mathrm{~mm})$ and severe pockets $(\geq 6 \mathrm{~mm})$ were scored on an ordinal scale of 0 to 4 and the highest score among the sextants was used as the individual's score. CPITN overestimated prevalence and severity in younger age groups and underestimated them among older subjects (16). The WHO included the measure of attachment loss in this index and renamed it as CPI (community periodontal index) to better capture the prevalence of disease.

In an attempt to capture the degree of severity and extent of periodontal disease in an index construct, the extent and severity index (ESI) was proposed in 1986 by Carlos (17) et al. This index summarizes the extent of previous disease activity with probing measurements to determine the degree of periodontal loss of attachment.

On October 6th 1993, the American Dental Association (ADA) introduced the Periodontal Screening and Recording (PSR) index, which was a modification of the CPITN, and represented a quick, reliable, reproducible method for identifying patients that require more complete evaluation of their periodontal health status (18). Gingivitis: PSR code 1 and 2 , and not more than one code 3 . 
Table 1. Periodontitis case definition in various studies.

\begin{tabular}{|c|c|c|c|c|}
\hline SI No. & Study Setting & Study Population & Study Design & Case Definition \\
\hline 1 & $\begin{array}{l}\text { The National Survey of Oral Health in } \\
\text { U.S. Employed Adults and Seniors (14) }\end{array}$ & $\begin{array}{l}\text { Employed persons } \\
19-65 \text { years }\end{array}$ & cross sectional survey & at least one tooth with PD $\geq 4 \mathrm{~mm}$ \\
\hline 2 & $\begin{array}{l}\text { World Health Organization Global Oral } \\
\text { Data Bank (23) }\end{array}$ & & & $\mathrm{PD} \geq 6 \mathrm{~mm}(\mathrm{CPITN}=4)$ \\
\hline 3 & Jordan (24) & $\begin{array}{l}\text { dental patients } 20-35 \text { years, } \\
\text { Jordan School of Dentistry }\end{array}$ & $\begin{array}{l}\text { age sex matched case } \\
\text { control }\end{array}$ & $>10$ pockets $\geq 4 \mathrm{~mm}$ \\
\hline 4 & $\begin{array}{l}\text { Boarding School, Gallup, } \\
\text { New Mexico (26) }\end{array}$ & $\begin{array}{l}\text { Native American } \\
\text { adolescents aged } \\
14-19 \text { years }\end{array}$ & Case control & $\begin{array}{l}\text { CAL } \geq 2 \mathrm{~mm} \text {, mesial site of first } \\
\text { permanent molar }\end{array}$ \\
\hline \multirow[t]{2}{*}{5} & \multirow[t]{2}{*}{ Porto Alegre, Brazil (27) } & \multirow[t]{2}{*}{$14-29$ years } & \multirow[t]{2}{*}{ Cross sectional } & $\begin{array}{l}\geq 4 \text { teeth with attachment loss } \geq 4 \mathrm{~mm} \\
\text { in } 14-19 \text { years }\end{array}$ \\
\hline & & & & $\begin{array}{l}\geq 4 \text { teeth with attachment loss } \geq 5 \mathrm{~mm} \\
\text { in } 20-29 \text { years }\end{array}$ \\
\hline 6 & $\begin{array}{l}\text { School students of the Province of } \\
\text { Santiago, Chile (28) }\end{array}$ & $\begin{array}{l}\text { high school urban students } \\
\text { aged } 12 \text { to } 21 \text { years }\end{array}$ & cross sectional survey & $\begin{array}{l}C A L \geq 1 \mathrm{~mm} \text { in } \geq 2 \text { site } \\
C A L \geq 1 \mathrm{~mm} \text { in } \geq 2 \text { interprox site } \\
C A L \geq 3 \mathrm{~mm} \text { in } \geq 1 \text { site } \\
C A L \geq 3 \mathrm{~mm} \text { in } \geq 1 \text { interprox site }\end{array}$ \\
\hline \multirow[t]{2}{*}{7} & \multirow[t]{2}{*}{$\begin{array}{l}\text { Guangdong Province in Southern } \\
\text { China (29) }\end{array}$} & $\begin{array}{l}\text { 35-44 (factories \& work } \\
\text { places) and of urban } \\
\text { and rural }\end{array}$ & \multirow[t]{2}{*}{ cross sectional survey } & $\geq 2$ sextants with $\geq 4 \mathrm{~mm} \mathrm{CAL}$ \\
\hline & & 65-74 adults (houses) & & $\geq 2$ sextants with $\geq 6 \mathrm{~mm} \mathrm{CAL}$ \\
\hline 8 & Adelaide, Australia (30) & $\begin{array}{l}45-54 \text { year old derived from } \\
\text { a random sample }\end{array}$ & cross sectional survey & $\begin{array}{l}\mathrm{LOA} \geq 4 \mathrm{~mm} \\
\mathrm{LOA} \geq 5 \mathrm{~mm} \\
\mathrm{LOA} \geq 6 \mathrm{~mm}\end{array}$ \\
\hline 9 & $\begin{array}{l}\text { National survey on oral health of school } \\
\text { children (31) }\end{array}$ & School children $13-19$ years & cross sectional & $\begin{array}{l}\text { at least four teeth with } C A L \geq 3 \mathrm{~mm} \\
\text { at least one tooth with } C A L \geq 3 \mathrm{~mm}\end{array}$ \\
\hline 10 & $\begin{array}{l}5 \text { contiguous North Corilina } \\
\text { counties (32) }\end{array}$ & Persons $65+$ years & cross sectional & $\begin{array}{l}\geq 4 \text { sites with } C A L \geq 5 \mathrm{~mm} \text { and one of } \\
\text { these same sites with } P D \geq 3 \mathrm{~mm}\end{array}$ \\
\hline 11 & US (33) & US population. NHANES III & cross sectional & $\begin{array}{l}\geq 1 \text { site with both probing depth and } \\
\text { Clinical attachment level } \geq 4 \mathrm{~mm}\end{array}$ \\
\hline 12 & US NHNAES III (34) & $\begin{array}{l}\text { US population never used } \\
\text { tobacco NHANESIII }\end{array}$ & cross sectional & $\begin{array}{l}\text { attachment loss of } \geq 3 \mathrm{~mm} \text { and pocket } \\
\text { depths of } \geq 4 \mathrm{~mm} \text { in same tooth }\end{array}$ \\
\hline 13 & Australia national survey (35) & Australian population & cross sectional survey & $\begin{array}{l}\text { moderate-severe periodontitis: } \geq 2 \\
\text { interproximal sites (not on same tooth) } \\
\text { with } \geq 4 \mathrm{~mm} C A L \text { or } \geq 2 \text { interproximal } \\
\text { sites with } \geq 5 \mathrm{~mm} \text { PPD (not on same } \\
\text { tooth) } \\
\text { severe periodontitis: } \geq 2 \text { interproximal } \\
\text { sites (not on same tooth) with } \\
\geq 6 \mathrm{~mm} \text { CAL and } \geq 1 \text { interproximal } \\
\text { sites with } \geq 5 \mathrm{~mm} \text { PPD. }\end{array}$ \\
\hline 14 & US (38) & HMO US Minneapolis & case control & mean $P D \geq 3 \mathrm{~mm}$ \\
\hline 15 & US Veteran Affairs Medical Center (39) & US patients & case control & mean PD \\
\hline 16 & NHANES III (40) & $\begin{array}{l}\text { Non institutionalized US } \\
\text { population } \geq 20\end{array}$ & cross sectional survey & $\begin{array}{l}\text { mean CAL } 0-0.99 \mathrm{~mm} \\
\text { mean CAL } 1.00-1.99 \mathrm{~mm} \\
\text { mean CAL } 2.00-2.99 \mathrm{~mm} \\
\text { mean CAL } 3.00-3.99 \mathrm{~mm} \\
\text { mean CAL } 4.00+\mathrm{mm}\end{array}$ \\
\hline 17 & Metropolitan community, US (41) & $\begin{array}{l}\text { Broadly defined population } \\
\text { sampled to include persons } \\
\text { with wide variation in } \\
\text { attachment loss. }\end{array}$ & $\begin{array}{l}\text { cross sectional survey, } \\
\text { case control study }\end{array}$ & $\begin{array}{l}\text { mean } C A L>3 \mathrm{~mm} \\
\text { mean } \mathrm{LOA}>4 \mathrm{~mm}\end{array}$ \\
\hline 18 & Thailand (42) & $\begin{array}{l}\text { Retired employees of Electric } \\
\text { company, } 50-73 \text { years }\end{array}$ & cross sectional & $\begin{array}{l}\text { mild periodontitis mean } C A L<2.5 \mathrm{~mm} \\
\text { moderate periodontitis mean } \\
\text { CAL } 2.5-3.9 \mathrm{~mm} \\
\text { severe periodontitis mean } \\
\mathrm{CAL} \geq 4.0 \mathrm{~mm}\end{array}$ \\
\hline 19 & Boston and New England US (43) & Hospital patients & Cross sectional & $\begin{array}{l}\text { Moderate } 2.4-3.4 \mathrm{~mm} \text { mean CAL } \\
\text { Severe }>3.4 \mathrm{~mm} \text { mean CAL }\end{array}$ \\
\hline 20 & Orlando, Florida US (44) & $\begin{array}{l}\text { Patients attending military } \\
\text { dental clinic }\end{array}$ & Cross sectional & $\begin{array}{l}\text { Early periodontitis: } \mathrm{BOP} \& \mathrm{PD}<5 \mathrm{~mm} \\
\text { Moderate/severe periodontitis: } \mathrm{BOP} \& \\
\mathrm{PD} \geq 5 \mathrm{~mm} \text {, furcation involvement or } \\
\text { radiographic bone loss }\end{array}$ \\
\hline
\end{tabular}


Periodontitis: code 3 in two or more sextants or at least one sextant with code 4.

As our understanding of periodontal disease and its susceptibility improved, the idea of using an index system as a case definition became less favored. To combine two incompatible measures such as different degrees of quality (gingiva) with absolute measurements of quantity (pocket depth and loss of attachment) into one index system was considered wrong (9). There was no need to convert the measure of periodontal loss, which was measured in millimeters, into a different unit because there seemed to be no added benefit. Quantifying and recording gingival inflammation does not contribute to the diagnosis of periodontitis (11).

\section{Thresholds of probing depth}

Although CPITN is not an index for assessing prevalence, it has been extensively used to do just that $(19,20,21,22)$. Periodontal surveys using CPITN are available to several countries from databases at the World Health Organization Global Oral Data Bank (23). Based on this index, severe disease was defined as the presence of least one site with a PD of $\geq 6 \mathrm{~mm}(\mathrm{CPITN}=4)$. The survey (14) on US employed adults and seniors based diagnosis on the presence of at least one tooth with $\mathrm{PD} \geq 4 \mathrm{~mm}$ or $5 \mathrm{~mm}$. The Jordan study $(24,25)$ on dental patients considered patients with more than 10 sites with pockets $(\geq 4 \mathrm{~mm})$ as affected. These data indicate, that subjects have been classified based on severity and extent of periodontal pockets.

\section{Thresholds of clinical attachment level}

In a risk factor study on adolescents, Carlos (26) et al. defined disease as CAL $\geq 2 \mathrm{~mm}$ in any of the mesial sites of the first permanent molars. Using measurements of $2 \mathrm{~mm}$ or more for diagnosis of attachment loss was considered conservative because it did not account for the measurement error. However, this could have decreased the strength of the association.

In a cross sectional survey of young individuals by Susin (27) et al., the prevalence of aggressive periodontitis and its association with various variables including smoking were assessed. Disease classification of aggressive periodontitis was given as follows:

1. 14 to 19 years of age: $\geq 4$ teeth with attachment loss $\geq 4 \mathrm{~mm}$

2. 20 to 29 years of age: $\geq 4$ teeth with attachment loss $\geq 5 \mathrm{~mm}$

In a cross sectional survey (28) of students ages 12 and 21 years, six sites on all first and second molars as well as all incisors present, were inspected for attachment loss. Teeth that had previously been reported to have the highest occurrence of attachment loss were selected. Prevalence was calculated for individuals with at least one site with attachment loss $\geq 1 \mathrm{~mm}, 2 \mathrm{~mm}$ or $3 \mathrm{~mm}$. The case definition used for odds ratio calculation was $\geq 1 / 2$ sites with $\geq 1 \mathrm{~mm}$ attachment loss, and $\geq 1$ site with $\geq 3 \mathrm{~mm}$ attachment loss. Interproximal measures were taken because periodontal disease was the only plausible cause for attachment loss in these areas.

A survey (29) in Southern China considered at least 2 sextants with a CAL $\geq 4 \mathrm{~mm}$ and $6 \mathrm{~mm}$ as disease in patients 35-44 years in age and 65-74 years in age, respectively. A survey (30) in Australia on adults 45-54 years in age, periodontitis was diagnosed at thresholds of 4, 5 and $6 \mathrm{~mm}$. A US survey (31) on school children reported that children were considered to have disease when at least 4 teeth had a $\mathrm{CAL} \geq 3 \mathrm{~mm}$.

\section{Combination of threshold of probing depth and clinical attachment level}

In a study (32) on older men in North Carolina, case definition was used to identify individuals with severe disease appropriate for their age. To differentiate between people with a more generalized and more severe level of disease from others, the distributions of attachment loss severity scores and pocket depth scores in sites with attachment loss were used. This process resulted in a definition that stated that the more severely affected group had $\geq 4$ sites with CAL $\geq 5 \mathrm{~mm}$ and that at least one of these sites had a PD $\geq 3 \mathrm{~mm}$. This definition resulted in $16 \%$ of the subjects in the white population and $46 \%$ of subjects in the black population as being classified as severely affected. The authors considered this definition to be appropriate, given the epidemiology of the disease in this group and the clinical concern generated by such a definition.

Tomar and Asma (33) analyzed NHANES III data to find the risk associated with smoking. Periodontitis was defined as presence of $\geq 1$ site with $\mathrm{CAL} \geq 4 \mathrm{~mm}$ and $\mathrm{PD} \geq 4 \mathrm{~mm}$. The rationale for this definition was that the prevalence of $\geq 1$ site with $\mathrm{PD} \geq 4 \mathrm{~mm}$ is fairly constant across age groups among US adults, ranging from $22.2 \%$ among subjects ages $30-39$ years, $25.9 \%$ among subjects ages 50-59 years, and $17.2 \%$ among subjects ages $80-90$ years. The prevalence of $\geq 1$ site of $C A L \geq 4 \mathrm{~mm}$ was strongly associated with age, ranging from $17.5 \%$ in the $30-39$ year age group to $71.1 \%$ in the 80-90 year age group. The present case definition included PD and CAL, therefore, the prevalence was not confounded by age and pseudopockets, which were not classified as disease.

In a study (34) using the NHANES III data to assess the effects of second-hand smoking on periodontitis, the presence of $\geq 1$ sites with a CAL of $\geq 3 \mathrm{~mm}$ and a PD of $\geq 4 \mathrm{~mm}$ (at the same site) was used as an indicator of periodontal disease.

The national survey (35) of Australia used the CDC Working group (2007) consensus case definition for severe and moderate periodontitis. Instead of buccal or lingual sites, interproximal sites were considered because the disease usually begins and is most severe at interproximal sites and because this minimizes the effects of gingival recession on the accuracy of the PD measurements (36). The case definition requires at least one site with $\mathrm{PD} \geq 5 \mathrm{~mm}$, in part to rule out patients who have been treated successfully but still have attachment loss or have attachment loss not resulting 
from periodontitis. The threshold for CAL was set at $\geq 6 \mathrm{~mm}$ based on the clinical criteria for "established periodontitis" set by Machtei (37) et al.

\section{Mean probing depth}

In an association study (38) which looked at smoking and periodontal status, the presence of more severe periodontal disease was defined as a mean $\mathrm{PD} \geq 3.5 \mathrm{~mm}$. In a case control study, mean PD was used to compare the periodontal status of the groups with and without diabetes (39).

\section{Mean clinical attachment level}

In a study by Hyman and Reid (40), which involved data from NHANES III in an attempt to find an association and its strength between various variables, mean CAL was used as the measure of periodontitis and was categorized into the following five groups: 0-0.99, 1.00-1.99, 2.00-2.99, 3.00-3.99 mm, and $\geq 4.00 \mathrm{~mm}$. Severe disease included $10 \%$ of the population in each age range with the greatest mean CAL. For those in the 20-49-year age range, the mean LOA was found to be $\geq 1.58 \mathrm{~mm}$ mean LOA, while for those aged $\geq 50$ years the threshold was $3.39 \mathrm{~mm}$.

In a cross sectional survey (41) of a broadly defined population that was sampled to include a wide variation of attachment loss, periodontal disease was classified by stratifying mean CAL into the following 5 ordered categories: healthy (0 to $1 \mathrm{~mm} \mathrm{CAL})$; low (1.1 to $2.0 \mathrm{~mm}$ CAL); moderate (2.1 to $3.0 \mathrm{~mm} \mathrm{CAL}$ ); high (3.1 to $4.0 \mathrm{~mm}$ CAL); and severe (4.1 to $8.0 \mathrm{~mm} \mathrm{CAL}$ ).

Torrungruang (42) et al. defined disease based on CAL in a study on Thai elders. Participants were classified as having mild periodontitis (mean $\mathrm{CAL}<2.5 \mathrm{~mm}$ ), moderate periodontitis (mean CAL 2.5 to $3.9 \mathrm{~mm}$ ), and severe periodontitis (mean $\mathrm{CAL} \geq 4.0 \mathrm{~mm}$ ).

Haffajee and Socransky (43) studied the role of smoking in periodontitis patients. The outcome variable, mean CAL, was divided into 3 sub-categories as follows: $<2.4,2.4-3.4$ and $>3.4 \mathrm{~mm}$. The mean CAL cutoffs were the $33 \mathrm{rd}$ and $66 \mathrm{th}$ percentiles of the entire subject distribution.

\section{Other definitions}

In an association study, Horning (44) used a combination of various disease measures to define a case. The definitions were as follows: 1) Gingivitis: bleeding on probing (BOP), and PD 0 to $3 \mathrm{~mm}$; Early Periodontitis: BOP, PD 3 to $5 \mathrm{~mm}$; Moderate Periodontitis: BOP, PD 5 to $7 \mathrm{~mm}$, or radiographic bone loss up to one third of the root length, or Class I furcation exposure; Advanced Periodontitis: BOP, PD $>7 \mathrm{~mm}$, or radiographic bone loss greater than one third of the root length, or Class II or III furcation exposures. Diagnostic criteria were selected based on the intent of the Periodontal Treatment Needs System and the Community Periodontal Index of Treatment Needs because the authors felt that for any diagnosis to be meaningful, it should properly lead to the type or degree of therapeutic efforts needed. For this reason, the limit for early periodontitis was set at $5 \mathrm{~mm}$, which is the limit for predictably effective closed root preparation; and the depth for advanced periodontitis was set at $7 \mathrm{~mm}$ because of a general consensus that this is severe.

In a case control study (45) involving smokers and non smokers to understand the reason for variation of the risk estimates in various studies, 133 smokers and 242 nonsmokers ages 20-69 years were divided into two cohorts and compared using a range of case definitions for periodontitis. The definition included several criteria based on clinical PD and radiographic measurement of bone height. Regarding PD, two levels (critical levels, 5 and $6 \mathrm{~mm}$ ) were used. For a critical level of $5 \mathrm{~mm}$, i.e. a PD of $\geq 5 \mathrm{~mm}$, pocket frequencies of $1 \%, 5 \%, 10 \%$, and $15 \%$, respectively, were selected as cutoff points. For a critical level of $6 \mathrm{~mm}$, i.e. a $\mathrm{PD}$ of $\geq 6 \mathrm{~mm}$, pocket frequencies of $1 \%, 5 \%$, and $10 \%$ were the selected cutoff points. With regard to bone height, the 30 th, 25th, and 20th percentiles of the distribution were used as cutoff points. These cutoff points corresponded to a mean bone height level of $82 \%, 80 \%$, and $76 \%$, respectively, in cohort 1 , and $83 \%, 82 \%$, and $80 \%$, respectively, in cohort 2 . The relative risk was estimated from the odds ratio (OR) following logistic regression, with pocket frequency, bone height or combinations of pocket frequency and bone height, respectively, as the dependent dichotomous variable.

In a study (13) to assess differences between selected periodontal measures in a nationally representative sample of the United State (NHANES III) based on demographic and behavioral factors, the following case definitions to identify persons with various levels of periodontitis were used. Attachment Loss Extent Index (ALEI), Periodontal Status Measure (PSM), Attachment Loss (AL), and a derived CPI (dCPI) were studied as outcome variables (PI or summary measure variables). A dCPI subject-level score was determined through selection of the lowest of the two quadrant scores according to CPI. For the ALEI score, the number of dental sites per person affected by CAL was summed and divided by the number of dental sites evaluated, and finally multiplied by 100 . This percentage was categorized into five groups: $0-4 \%$ of sites affected, $5-24 \%$ of sites affected, $25-49 \%$ of sites affected, $50-74 \%$ of sites affected, and $75 \%$ or more of sites affected. An indicator of past periodontal disease, clinical AL was defined as a minimum of $2 \mathrm{~mm}$ of measured loss. These criteria were established to reflect extent and severity index. For the AL score, clinical AL measured in millimeters at each dental site was summed and divided by the number of sites examined to produce a mean clinical AL score. This score was categorized into five groups: 0-1 mm of average clinical AL, 1.1-1.5 mm of average clinical AL, 1.6-2.0 mm clinical AL, 2.1-2.5 mm of average clinical AL, and $\geq 2.6 \mathrm{~mm}$ average clinical AL. These five categories were chosen based on findings from a preliminary data analysis that identified distinctive inflection points on a curve, when severity of clinical AL was plotted against extent of clinical AL. A person's PSM score was derived based on the worst tooth condition observed for each quadrant. Then, the overall PSM score was determined by selecting the lowest of the two quadrant scores. The 
PSM scoring range of 0-4 is similar to CPI, but unlike the $\mathrm{CPI}$, the PSM incorporates clinical AL and dental furcation status.

Albandar et al. classified individuals according to extent and severity of periodontal disease using the following criteria (46):

- Advanced periodontitis: 1) 2 or more teeth (or $30 \%$ or more of the teeth examined) with $\mathrm{PD} \geq 5 \mathrm{~mm}$, or 2) 4 or more teeth (or $60 \%$ or more of the teeth examined) with $\mathrm{PD} \geq 4 \mathrm{~mm}$, or 3 ) one or more posterior teeth with grade II furcation involvement.

- Moderate periodontitis: 1) 1 or more teeth with PD $\geq 5 \mathrm{~mm}$, or 2) 2 or more teeth (or $30 \%$ or more of the teeth examined) with $\mathrm{PD} \geq 4 \mathrm{~mm}$, or 3 ) one or more posterior teeth with grade I furcation involvement and accompanied with $\mathrm{PD} \geq 3 \mathrm{~mm}$.

- Mild Periodontitis: 1) 1 or more teeth with $\geq 3 \mathrm{~mm}$ probing depth, or 2) one or more posterior teeth with grade I furcation involvement.

In a study (32) on older men of North Carolina, loss of attachment for each person was categorized by the site with the highest loss of attachment.

\section{Discussion}

A case definition can be developed based on the following (47):

1. The medical model of "presence or absence" of the disease;

2. A definition of disease as people with the highest percent $(5,10,15 \%$, etc. $)$ of sites with attachment loss;

3. Determination of a clinically significant cutoff point; or

4. Use of a combination of these definitions.

Criterion-based definitions (presence or absence, clinically significant) are more comparable across studies than population-based definitions (model 2), which depend on the distribution of disease in the study population (47).

The classification of periodontal disease like any disease is based on arbitrary or artificial categories, which are constructed more for utility than to express actual disease characteristics. In the absence of knowledge about causal criteria, manifestational criteria provide the only basis for categorization (48). Although a unanimous definition of periodontal disease does not exist, there is a generalized agreement that certain clinical and radiographic manifestations such as pocket probing depth, attachment loss, and bone loss beyond a given limit (critical level) are diagnostic for the disease.

To establish case definitions for periodontitis, one must determine the threshold values for CAL, PD, or both at a given site that provide unequivocal evidence of periodontitis at that site. Selection of threshold values is critical. Clinical parameters used to describe periodontal breakdown must truly represent loss of attachment at the histological level, and avoid artifacts that are due to individual variation and/ or increased probe penetration (37).
CAL has a strong correlation with the histological definition of periodontitis, i.e. apical migration of the junctional epithelium beyond the CEJ with loss of connective tissue attachment and alveolar bone. CAL is used to assess the severity of periodontitis because it represents cumulative periodontal destruction over a person's lifetime. However, CAL does not reflect the nature or activity of periodontitis, which is better reflected in probing depth. The use of probing pocket depth measurements, although often correlated with periodontitis, suffers from the following two main deficiencies: 1) an increase in pocket depth may result from gingival edema (pseudopockets); and 2) increased PD may be minimized or masked by concomitant gingival recession (37). In younger populations, both $\mathrm{PD}$ and CAL are accepted as measures of periodontal status as both have a strong correlation. Attachment loss seems to continue past middle age. However, as gingival recession occurs, increases in PD fail to keep pace with increases in CAL, and PD and CAL no longer correlate (49). Using PD as the only measure of periodontal status or disease progression could be misleading because disease severity could be underestimated significantly, especially in older populations. Conversely, models of disease progression based on CAL alone have had only moderate success; for example, they have only low to moderate sensitivity (i.e., determining who will get the condition) (50). Use of CAL alone could mistakenly include some periodontally healthy sites because attachment loss can accompany non-inflammatory gingival recession (36). A patient or a tooth with periodontitis can be treated successfully or the disease can resolve spontaneously without a return of CAL to normal.

Combinations of PD and CAL at specific levels have been used under the rationale that they represent both cumulative tissue destruction (CAL) and current pathology (PD) (36). The prevalence with PD is fairly constant across age groups, while with CAL, prevalence is strongly associated with age (33). The prevalence using case definition including PD and CAL will not be confounded by age, and pseudo-pockets will not be classified as disease (33). These observations provide a strong argument for the use of both PD and CAL in determining case definitions.

No matter which definition is used, the investigator must show that the threshold value chosen to define a case (how many millimeters of attachment loss) is not likely to be attributed to measurement error (47). Machtei (37) et al. calculated that CAL must be $>5.5 \mathrm{~mm}$ to ensure that periodontally normal sites are excluded from the disease category. This threshold was calculated from two studies. A histological study of Gargiulo (51) et al. found that the mean distance between the CEJ and the bone crest was $1.08 \mathrm{~mm}$ with normal values ranging from $0.04 \mathrm{~mm}$ to $3.36 \mathrm{~mm}$. Thus, a distance greater than $3.36 \mathrm{~mm}$ is required to establish true periodontal attachment loss. The second study cited by Machtei (Christersson et al. 1991) found that a standard deviation (SD) of $1.07 \mathrm{~mm}$, for examiners when measuring CAL (37), (CAL greater than $5.5 \mathrm{~mm}$, based upon maximal normal CEJ-bone crest distance $(3.36 \mathrm{~mm})+$ twice 
SD $(2.14 \mathrm{~mm}))$ must be present to establish true loss of periodontal attachment. Horning (44) et al. set his critical value for periodontal measure based on the type of treatment recommended. Albandar (46) et al. included furcation involvement in his case definition as it was considered as a sign of extensive loss of periodontal tissues.

However, once a decision has been made on a critical level of the criterion or set of criteria, the frequency of the criterion/criteria required to discriminate between disease and non-disease, i.e., for the classification of an individual as a case or not, remains to be decided. While CAL $\geq 6 \mathrm{~mm}$ is likely to reflect true attachment loss, the question remains as to whether this clinical sign will be exclusively associated with periodontitis (37). Local etiologic factors, such as overhanging amalgam restorations, ill-fitting crowns, and/ or proximal caries, may cause isolated areas of attachment loss that are not reflective of the overall periodontal status of these patients. Consequently, one isolated site of $\mathrm{CAL} \geq 6 \mathrm{~mm}$ might reflect local phenomena and not "true" periodontitis.

A prevalence of periodontal disease greater than $10 \%$ in the normal adult population, however, does not seem reasonable and would imply an unnecessary large proportion of false positives (45). Individuals who are susceptible to the occurrence of generalized oral attachment loss may have different risk factors or different interactions between risk factors than those who have only 1 or 2 sites with attachment loss. Including the variable of extent in the case definition will be more important in case control studies than in prevalence studies.

In general, when investigators are interested in the rate of disease progression over multiple time periods as related to site and person characteristics or the effects of treatment, then attachment loss can be used as a continuous variable (the amount of attachment loss in millimeters) and disease can be defined as a point along that continuum. Conversely, if the investigator is interested in how site and person characteristics are related to the presence or absence of active disease during a specified time period, then the outcome measure is dichotomous (an individual is determined to be a case or a non-case depending on whether the person had 1 or more sites experience attachment loss above a predefined threshold; e.g., $1 \mathrm{~mm}$ ).

Mean attachment loss, although not intended as an indication of treatment needs, provides an estimate of the historical amount of periodontal destruction in a given patient (41). The variation in mean attachment loss enabled the case-control analysis as a gradient or continuum in severity of periodontal destruction. It has been reported that mean values are beneficial in exploring trends, describing differences in disease severity, and examining relationships between disease and potential predictors, such as oral microbe load or smoking status, and between probed clinical $\mathrm{AL}$ and radiographic alveolar bone loss (13).

The criteria for identifying periodontal disease severity differ among studies. Some studies use radiographic assessments of bone level, some use mean CAL or \% sites with CAL above a certain cutoff point, and others use a combination of CAL and probing depth measurements $(13,42)$. Despite these variations, it has been suggested that severe periodontal destruction is probably not developed by more than $10 \%$ to $15 \%$ of the individuals.

Case definition for prevalence surveys and risk factor studies differ in their sensitivity and specificity. A definition is employed for the prevalence estimation to include all individuals with periodontitis. A stricter definition is used for association studies where more accurate risk estimation is important and hence less false positive results are preferred. This was highlighted by the CDC working group, which proposed a severe and a moderate definition for periodontitis (52). The case definition for severe periodontitis requires two or more interproximal sites (not on the same tooth) with $\mathrm{CAL} \geq 6 \mathrm{~mm}$ and at least one interproximal sites with $\mathrm{PD} \geq 5 \mathrm{~mm}$. Moderate periodontitis was defined as two or more interproximal sites (not on the same tooth) with $\mathrm{CAL} \geq 4 \mathrm{~mm}$ or two or more interproximal sites with $\mathrm{PD} \geq 5 \mathrm{~mm}$ (also not on the same tooth).

The effect of partial recording has to be considered when the role of case definition is described. This review does not go into the role of partial recordings in deciding on a case definition. The factors which affect the accuracy of measurement, including the tools and effect of inflammation, are not considered here, as it is outside the scope of the study.

Attachment loss as measured in case-control and crosssectional studies is an accretion measure, but this measure is taken only on surviving teeth (9). Thus, the number of missing teeth also affects how seriously epidemiological measures underestimate disease. In identifying a case definition for risk assessment, a different approach is employed. The goal of risk assessment is to predict new disease, therefore, the decision on a definition will be influenced by the incidence of the disease, the perceived seriousness of the disease, and the reason for a need to predict the disease (47). These issues are not discussed in the review.

\section{Final considerations}

The need for a reliable and valid periodontal case definition has recently grown, as researchers elucidate the complex etiology and pathogenesis of periodontal diseases and the relationship between systemic and periodontal infections. These summary measures are needed for continued periodontal disease surveillance in populations. At present, the combined use of probing depth and clinical attachment level is advocated in defining disease in population studies. It is recommended that a uniform case definition be used for prevalence surveys so that data can be compared between populations. A population specific case definition will be more suitable for association studies. This definition should reflect the incidence, prevalence and perceived seriousness of the disease. 
1. Page RC, Eke PI. Case definitions for use in population-based surveillance of periodontitis. J Periodontol 2007;787S:1387-99.

2. Russell AL. The Periodontal Index. J Periodontol 1967;38:Suppl:585-91.

3. Russell AL. Epidemiology of periodontal disease. Int Dent J 1967;17:282-96.

4. Russell AL. The prevalence of periodontal disease in different populations during the circumpubertal period. J Periodontol 1971;42:508-12.

5. Cutress TW, Hunter PB, Beck DJ, de Souza P. A comparison of WHO periodontal status index with the periodontal and oral hygiene indices. Community Dent Oral Epidemiol 1978;6:245-52.

6. Wolf DL, Lamster IB. Contemporary concepts in the diagnosis of periodontal disease. Dent Clin North Am 201 1;55:47-61.

7. Greenstein G. Changing periodontal concepts: treatment considerations. Compend Contin Educ Dent 2005;26:81-2,84-6,88 passim;quiz 98,127.

8. Van Dyke TE, Tohme ZN. Periodontal diagnosis: evaluation of current concepts and future needs. J Int Acad Periodontol 2000;2:71-8.

9. Beck JD, Löe H. Epidemiological principles in studying periodontal diseases. Periodontol 2000 1993;2:34-45

10. Dietrich T, Kaye EK, Nunn ME, Van Dyke T, Garcia RI. Gingivitis susceptibility and its relation to periodontitis in men. J Dent Res 2006;85:1134-7.

11. Russell AL. A system of classification and scoring for prevalence surveys of periodontal disease. J Dent Res 1956;35:350-9.

12. Douglass. Cross-sectional studies in periodontal disease: current status and implications for dental practice. Adv Dent Res 1993;7:25-31.

13. Dye BA, Selwitz RH. The relationship between selected measures of periodontal status and demographic and behavioural risk factors. J Clin Periodontol 2005;32:798-08.

14. Albandar JM. Periodontal diseases in North America. Periodontol 2000 2002;29:31-69.

15. Ramfjord SP. The Periodontal Disease Index (PDI). J Periodontol 1967;386S:602-10.

16. Do GL, Spencer AJ, Roberts-Thomson K, Ha HD. Smoking as a risk indicator for periodontal disease in the middle-aged Vietnamese population. Community Dent Oral Epidemiol 2003;31:437-46.

17. Carlos JP, Wolfe MD, Kingman A. The extent and severity index: a simple method for use in epidemiologic studies of periodontal disease. J Clin Periodontol 1986;13:500-5.

18. Lemuel. The application of Periodontal Screening and Recording (PSR) in a military population. J Contemp Dent Pract 2003;4:36-51.

19. Klinge B, Norlund A. A socio-economic perspective on periodontal diseases: a systematic review. J Clin Periodontol 2005;32S6:314-25.

20. Katz J, Peretz B, Sgan-Cohen HD, Horev T, Eldad A. Periodontal status by CPITN, and associated variables in an Israeli permanent force military population. J Clin Periodontol 2000;27:319-24.

21. Youn-Hee Choi,Hye-Jin Baek, Keun-Bae Song, Ji-Youn Han, Hojang Kwon, Sang Gyu Lee. Prevalence of periodontitis and associated risk factors in Korean adults: Korean National Oral Health Survey 2006, J Korean Acad Periodontol 2009;39:261-8.

22. Moreira Rda S, Nico LS, Tomita NE. Oral health conditions among the elderly in Southeastern São Paulo State. J Appl Oral Sci 2009;17:170-8.

23. World Health Organization. The WHO Global Oral Health Data Bank. Geneva World Health Organization 2003

24. Miller AJ, Brunelle JA, Carlos JP, Brown LJ, Löe H. August 1987. Oral health of United States adults. The national survey of oral health in U.S. employed adults and seniors: 1985-86. NIH Publication no. 87-2868. Bethesda, Maryland: U.S. Department of Health and Human Services, National Institutes of Health 1987.

25. Al-Wahadni A, Linden GJ. The effects of cigarette smoking on the periodontal condition of young Jordanian adults. J Clin Periodontol 2003; 30:132-7.

26. Carlos JP, Wolfe MD, Zambon JJ, Kingman A. Periodontal disease in adolescents: some clinical and microbiologic correlates of attachment loss. J Dent Res 1988;67:1510-4.

27. Susin C, Albandar JM. Aggressive periodontitis in an urban population in southern Brazil. J Periodontol 2005;76:468-75.

28. Lopez, Fernandez, Jara, Baelum. Epidemiology of Clinical attachment loss in adolescents. J Periodontol 2001;72:1666-74

29. Corbet EF, Wong MC, Lin HC. Periodontal conditions in adult Southern Chinese. J Dent Res 2001;80:1480-5.

30. Brennan DS, Spencer AJ, Roberts-Thomson KF. Periodontal disease among 45-54 year olds in Adelaide, South Australia. Aust Dent J 2007;52:55-60.

31. Albandar JM, Brown LJ, Löe H. Clinical features of early onset periodontitis. J Am Dent Assoc 1997; 128:1393-9.

32. Beck JD, Koch GG, Rozier RG, Tudor GE. Prevalence and risk indicators for periodontal attachment loss in a population of older community-dwelling blacks and whites. J Periodontol 1990;61:521-8. 
33. Tomar SL, Asma S. Smoking-attributable periodontitis in the United States: findings from NHANES III. National Health and Nutrition Examination Survey. J Periodontol 2000;71: 743-51.

34. Arbes SJ Jr, Agústsdóttir H, Slade GD. Environmental tobacco smoke and periodontal disease in the United States. Am J Public Health 2001;91:253-7.

35. Do LG, Slade GD, Roberts-Thomson KF, Sanders AE. Smoking-attributable periodontal disease in the Australian adult population. J Clin Periodontol 2008;35:398-404.

36. Borrell LN, Papapanou PN. Analytical epidemiology of periodontitis. J Clin Periodontol 2005;32S: 132-58

37. Machtei EE, Christersson LA, Grossi SG, Dunford R, Zambon JJ, Genco RJ. Clinical criteria for the definition of "established periodontitis". J Periodontol 1992;63:206-14.

38. Stoltenberg JL, Osborn JB, Pihlstrom BL, Herzberg MC, Aeppli DM, Wolff LF et al. Association between cigarette smoking, bacterial pathogens, and periodontal status. J Periodontol 1993;64:1225-30.

39. Khader YS, Rice JC, Lefante JJ. Factors associated with periodontal diseases in a dental teaching clinic population in northern Jordan. J Periodontol 2003;74:1610-7.

40. Hyman JJ, Reid BC. Epidemiologic risk factors for periodontal attachment loss among adults in the United States. J Clin Periodontol 2003;30:230-7.

41. Grossi SG, Zambon JJ, Ho AW, Koch G, Dunford RG, Machtei EE et al. Assessment of risk for periodontal disease. I. Risk indicators for attachment loss. J Periodontol 1994;65:260-7.

42. Torrungruang K, Tamsailom S, Rojanasomsith K, Sutdhibhisal S, Nisapakultorn K, Vanichiakvong $\mathrm{O}$ et al. Risk indicators of periodontal disease in older Thai adults. J Periodontol 2005;76:558-65.

43. Haffajee AD, Socransky SS. Relationship of cigarette smoking to attachment level profiles. J Clin Periodontol $2001 ; 28: 283-95$.

44. Horning GM, Hatch CL, Cohen ME. Risk indicators for periodontitis in a military treatment population. J Periodontol 1992;63:297-02.

45. Bergström J. Tobacco smoking and risk for periodontal disease. J Clin Periodontol 2003;30:107-13

46. Albandar JM, Brunelle JA, Kingman A. Destructive periodontal disease in adults 30 years and older in the US. J Periodontol 1999;70:13-29.

47. Beck JD. Methods of assessing risk of Periodontitis and developing multifactorial models. J Periodontol 1994;65:468-78.

48. Bliche, Joshipura, Eke. Validation of self reported periodontal disease: A systematic review. J Dent Res 2005;84:881-90.

49. Brown LJ, Oliver RC, Loe H. Evaluating periodontal status of US employed adults. J Am Dent Assoc 1990;121:226-32.

50. Beck JD. Attachment loss trends in community dwelling older blacks and whites over 3 years. J Dent Res 1992;72:264.

51. Gargiulo AW, Frank MW, Orban B. Dimensions and relations of the dentogingival gingival junction in human. J Periodontol 1961;32:261-7.

52. Page RC, Eke PI. Case definitions for use in population-based surveillance of periodontitis. J Periodontol 2007;787S:1387-99. 